\title{
A relação virtuosa entre empreendedorismo e capital social: um estudo em empreendimentos de turismo em espaço rural em Portugal e no Brasil
}

\section{The virtuous relationship between entrepreneurship and social capital: a study on tourism rural businesses in Portugal and Brazil}

\section{Teresa Costa}

Instituto Politécnico de Setúbal, Escola Superior de Ciências Empresarias, Campus do IPS, Estefanilha, 2914 - 503 Setúbal, Portugal, teresa.costa@esce.ips.pt

\section{Simone Galina}

Universidade de São Paulo, Faculdade de Economia, Administração e Contabilidade - Avenida Bandeirantes, 3900 - Vila Monte Alegre, Ribeirão Preto - SP, 14040-905, Brasil, svgalina@usp.br

\begin{abstract}
Resumo
O presente estudo tem como principal objetivo compreender a relação entre capital social e criação e desenvolvimento de empreendimentos em Turismo em Espaço Rural. Através da estratégia de pesquisa de estudo de caso, este estudo analisa as redes sociais usadas pelos empreendedores, os recursos acedidos e os aspetos importantes relacionados com as dimensões do capital social (na fase de criação e desenvolvimento dos empreendimentos).

Os resultados sugerem que, nos casos estudados, as redes formais e informais são cruciais na mobilização de recursos económicos e não económicos. Em geral, a rede informal é importante na mobilização de recursos não-económicos, sendo nos casos brasileiros, igualmente importante na mobilização de recursos económicos. Relativamente à dimensão estrutural de capital social, foi possível verificar semelhanças na fase de criação, ou seja, predominância de uma configuração simples, familiar e adoção de uma gestão informal. Constatou-se, no entanto, evidências de uma crescente complexidade em projetos com elevado crescimento durante a fase de desenvolvimento. No que respeita às dimensões relacional e cognitiva ambas são relevantes em diferentes fases de projetos empreendedores, e à medida que estes vão crescendo e gerando mais valor, parece ocorrer uma maior identificação entre empreendedores e organizações comunitárias e agentes locais, aumentando a legitimidade do projeto e da cultura empreendedora da comunidade.
\end{abstract}

Palavras-chave: Empreendedorismo, capital social, redes, turismo em espaço rural, estudo de caso.

\section{Abstract}

This study aims to understand the relationship between social capital and the creation and development of enterprises in rural tourism. Through a case study research strategy, the study aims to understand the socia networks used by entrepreneurs, resources accessed and important aspects related to the dimensions of social capital (in creation and development phases of the entrepreneurial projects).

The results suggest that in the cases studied the informal and formal networks owned by entrepreneurs are crucial in mobilizing financial and non-financial resources, and in general, the informal network is crucial in mobilizing non-economic resources, and, in the Brazilian cases, also important in mobilizing financial resources. Regarding the structural dimension of social capital, it was possible to verify similarities in the creation phase, such as simple configuration, familiar and informal management adopted. There are, however, some evidence of an increasing complexity in projects with high growth during the development phase. Concerning the relational dimension and cognitive dimension both are relevant at different stages of entrepreneurial projects. As the projects are growing and creating value, there is a greater identification between entrepreneurs, and community organizations and local players, increasing the legitimacy of the enterprise and the entrepreneurial culture of the community.

Keywords: Entrepreneurship, social capital, social networks, rural tourism case study.

\section{Introdução}

Vários estudos evidenciam a importância do Turismo em Espaço Rural (TER) para a economia em geral e em particular para as economias locais (Mendonça, 2006; Meyer-Cech, 2005; Ohe\& Kurihara, 2013; Su, 2011). Também a Comissão Europeia (2006) reforça esta relação. Contudo, o processo de criação, renovação e desenvolvimento de novos negócios em Turismo em Espaço Rural não é um processo simples. Talvez por este motivo a investigação em turismo sobre formação dos novos negócios ainda não tenha sido encarada com a devida seriedade, adequada à complexidade do processo envolvido. Aliás, de um modo geral, até ao momento, os esforços da investigação são, na sua maioria, dedicados à compreensão das características e práticas de negócios de empresas estabelecidas, dando pouca importância quer aos fatores determinantes no processo de criação, quer no seu desenvolvimento e sustentabilidade, nomeadamente ao nível do capital social.

Similarmente a aplicação do conceito de capital social em estudos sobre empreendedorismo no turismo é ainda relativamente escassa, o que levou à necessidade de aprofundamento desta problemática que conduziu à questão de partida para este estudo: Existe uma relação virtuosa entre capital social e empreendedorismo em Turismo em Espaço Rural?

O estudo que se propõe tem como objetivo principal compreender a relação entre capital social e a criação e desenvolvimento do empreendedorismo em Turismo em Espaço Rural. Especificamente, o trabalho analisa as redes sociais usadas pelos empreendedores, os recursos acedidos pelos empreendedores e os aspetos relacionados com as dimensões do capital social, que foram determinantes na mobilização dos recursos nas diferentes fases do projeto (criação e desenvolvimento), considerando as dimensões estrutural, relacional e cognitiva apresentada por Nahapiest e Goshal (1998).

Organizado em duas partes, o estudo recorre, numa primeira parte, a uma revisão de literatura para o enquadramento teórico do tema, no que concerne ao empreendedorismo e capital social contextualizando no Turismo em Espaço Rural, assim como à diferenciação das redes formais das informais e o acesso a 
recursos em diferentes fases do processo empreendedor. Numa segunda parte é desenvolvida uma pesquisa exploratória, através de um estudo de campo suportado numa análise qualitativa. Nesta parte foram entrevistadas entidades ligadas ao Turismo em Espaço Rural no Brasil e em Portugal assim como, um conjunto de empreendedores de diferentes empreendimentos de Turismo em Espaço Rural no Brasil e em Portugal com o objetivo de se compreender uma possível relação virtuosa entre empreendedorismo e capital social neste tipo de empreendimentos.

\section{Revisão de literatura}

\subsection{Turismo rural e empreendedorismo}

O desenvolvimento rural, numa perspetiva de ocupação do espaço rural representa uma das preocupações da Política Regional da Europa (European Commission, 2011). De acordo com o Programa Operacional Regional 2014-2020 (QREN), o desenvolvimento rural deverá possuir três eixos de atuação: crescimento inteligente, crescimento sustentável e crescimento inclusivo.

Para Pego e Bernardo (2015), a desenvolvimento do mercado rural teve origem na reorganização económica e social da sociedade contemporânea, e consolidou-se a tomada de consciência da necessidade de novos investimentos e mudanças estruturais em zonas de baixa ocupação populacional e elevado envelhecimento.

Vários estudos têm sido produzidos que evidenciam a riqueza das zonas rurais e suas potencialidades turísticas e alguns autores referem que o património natural, histórico e cultural de muitas zonas rurais cria oportunidades para atividades relacionadas com o turismo (Dana, Gurau, \& Lasch, 2014). Contudo, estas zonas rurais são mais do que simples locais para o empreendedorismo e os seus atributos sociais e geográficos são de extrema relevância para o processo empreendedor (Johnstone \& Lionais, 2004). Estas especificidades exigem abordagens empreendedoras adaptadas, ou seja, geralmente as empresas são pequenas e os empreendedores muito atentos à vida e às necessidades da comunidade, valorizando e contribuindo para a identidade local (Steyaert \& Katz, 2004). Por outro lado, a exploração das oportunidades existentes nestas zonas rurais depende não só das características do território, mas também das decisões de gestão levadas a cabo e implementadas para o desenvolvimento territorial, que devem garantir uma boa relação entre os benefícios económicos e a preservação da identidade local (Murzyn-Kupisz, 2012).

\subsection{Capital social e empreendedorismo}

A literatura sobre empreendedorismo é rica e revela vários e diferentes esforços em torno da sua concetualização, não existindo uma definição universal sobre o empreendedorismo. Contudo, a investigação em turismo sobre a formação dos novos negócios ainda não foi encarada com a devida importância, e de um modo geral, até ao momento, os esforços da investigação são na sua maioria dedicados à compreensão das características e práticas de negócios de empresas estabelecidas (Getz \& Carlsen, 2005). Estes estudos têm-se focado particularmente em fornecer prescrições muito orientadas para a solução de problemas relacionados com a gestão dos negócios, apresentando poucas orientações para a criação e desenvolvimento dos novos negócios.
De acordo com Getz e Carlsen (2000), uma grande parte dos empreendedores do turismo, nos países ocidentais, são motivados por benefícios relacionados com o "estilo de vida" e não pelo lucro. A investigação sobre a capacidade para empreender enfatiza a importância do capital humano e a disponibilidade de recursos necessários. Este tema está longe de estar adequadamente resolvido na pesquisa em turismo. A segunda corrente destaca a influência do ambiente no estímulo e promoção de iniciativas empreendedoras, ou seja, na influência do mercado, da política ou das flutuações económicas e nos seus impactos à iniciativa empreendedora. Este estudo segue a primeira corrente de pesquisa, e está particularmente interessado em explorar a relação entre o capital social e a capacidade empreendedora no turismo rural.

A literatura existente sobre a criação de empresas pode ser organizada em duas correntes. A primeira delas foca-se na pessoa, ou seja, na propensão de um indivíduo e na sua capacidade para empreender e a segunda corrente destaca a influência do ambiente no estímulo e promoção de iniciativas empreendedoras, ou seja, na influência do mercado, da política ou das flutuações económicas e nos seus impactos à iniciativa empreendedora (Liao $\&$ Welsch, 2005). Este estudo segue a primeira corrente de pesquisa, e está particularmente interessado em explorar a relação entre o capital social e a capacidade empreendedora no turismo rural.

Por outro lado, a aplicação do conceito de capital social na pesquisa em turismo é relativamente escassa. Apesar da fraca atenção que tem sido dada ao papel do capital social no turismo, os estudos existentes parecem estar de acordo no que se refere à influência do capital social no aumento da participação da comunidade no desenvolvimento do turismo local (Ducci \& Teixeira, 2010; Nordin \& Westlund, 2009; Park, Lee, Choi, \& Yoon, 2012; Zhao, Ritchie, \& Echtner, 2011).

No entanto, a literatura revela diferentes perspetivas no que respeita à concetualização de capital social. Segundo Van der Gaag e Snijders (2004) existem duas perspetivas principais nos estudos sobre capital social: o capital social individual e o capital social coletivo. A primeira perspetiva valoriza o uso do capital social pelos indivíduos, tentando compreender e analisar a forma como estes investem em relações sociais, captam os recursos através destas relações que são determinantes para a geração de benefícios para as suas ações (Burt, 1992, 2001). A segunda perspetiva tenta compreender o modo como determinados grupos desenvolvem e mantêm o capital social com o recurso coletivo, assim como a forma como esse recurso coletivo aumenta as possibilidades de vida do grupo (Putnam, 2000).

Outra abordagem é a de Adler e Kwon (2002) que estrutura os estudos sobre capital social em três perspetivas: 1) capital social bridging ou externo, 2) capital social bonding ou interno e 3) uma junção das duas anteriores perspetivas. No entanto, a perspetiva multidimensional de Nahapiet e Ghoshal (1998) confere uma profundidade à análise deste tema. Estes autores definem capital social como a soma de um conjunto de recursos atuais e potenciais enraizados, disponíveis através e obtidas a partir da rede de relacionamentos de um individuo ou uma unidade social. Baseado nesta definição os autores identificaram três dimensões interligadas: a dimensão estrutural que envolve todo o tipo de 
ligações numa rede de relações sociais (configuração da rede), a dimensão relacional que refere-se à qualidade ou fortalecimento dos laços sociais e que depende geralmente da duração e da frequência da reciprocidade dos comportamentos (a confiança, as normas, as obrigações, a identificação com o grupo) e a dimensão cognitiva que abrange aspetos que dizem respeito ao conhecimento, representações, interpretações e sistemas de significado entre os atores (ver Figura 1).

Figura 1- Dimensões do Capital Social de Nahapiet e Ghoshal (1998)

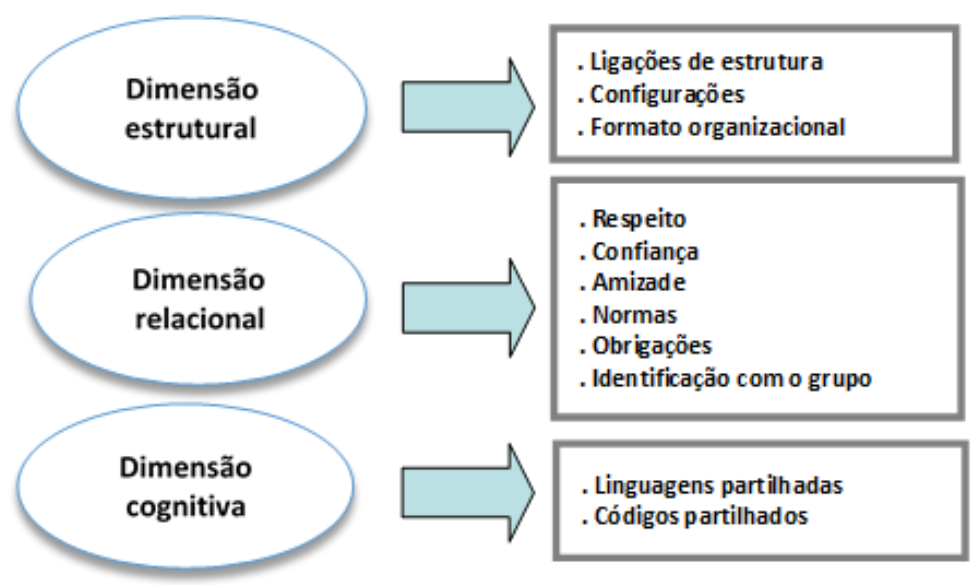

Fonte: Adaptado de Nahapiet e Ghoshal (1998).

Por natureza, o empreendedorismo envolve arriscar em domínios desconhecidos e informações fiáveis sobre o turismo podem aumentar a capacidade do potencial empreendedor, ajudar a compreender oportunidades emergentes, assim como ajudar a avaliar a viabilidade destas oportunidades. De acordo com Burt (1992) os benefícios de informações decorrentes da dimensão estrutural podem representar acesso, oportunidade e referências importantes. Segundo Tsai e Ghoshal (1998) numa dimensão estrutural, a localização de um ator e os contatos que o mesmo possui numa determinada estrutura social representam vantagens para o mesmo. Estes autores ainda afirmam que, esta dimensão pressupõe que os indivíduos podem utilizar os seus contatos pessoais para obter certas posições no trabalho, informações ou acesso a recursos específicos. A dimensão social pode também ter impactos relevantes na disponibilidade de recursos valiosos, como capital, espaço, facilidades, equipamento ou mão-de-obra. Muitas vezes os micro-empreendedores têm dificuldades em conseguir empréstimos bancários e, frequentemente, esse acesso é conseguido através da sua rede social.

Também o capital social relacional é muito importante no empreendedorismo uma vez que a experiência pessoal e a qualidade de interações passadas pode influenciar profundamente o sucesso das abordagens e dos compromissos do empreendedor. A confiança constitui um dos mais importantes laços sociais que pode contribuir para facilitar o fluxo de recursos e de informação, assim como aumentar o compromisso dos comportamentos cooperativos (Davidsson e Honig, 2003). De acordo com Inkpen e Tsang (2005) e no que refere aos benefícios decorrentes da informação, os laços sociais fortes conduzem a uma transferência de informações mais refinada e fidedigna e potenciam o conhecimento tácito.

No que se refere à dimensão cognitiva, Liao e Welsch (2005) especificam dois mecanismos através dos quais esta dimensão exerce influência sobre os empreendedores: a legitimidade organizacional e a cultura empreendedora. O primeiro mecanismo refere-se ao reconhecimento e aceitação da empresa pela sociedade. A não-aceitação da empresa junto da comunidade e por parte de outros stakeholders pode incorrer em pressões e antagonismos que, geralmente, contribuem para reduzir drasticamente a oportunidade de obter informações e recursos externos. Assim, contextualizando no turismo, certas formas controversas de turismo e descuido relativamente ao tipo de turistas que se atrai para a comunidade, podem condicionar de uma forma muito negativa o acesso aos recursos para o desenvolvimento dos negócios. Relativamente ao segundo mecanismo - cultura empreendedora - alguns estudos indicam que nas comunidades onde este tipo de cultura é predominante, as pessoas são mais propensas a entender comportamentos de risco, tolerar o fracasso, incentivar a independência financeira das gerações mais jovens e defender o auto-emprego, proporcionando assim o acesso a recursos aos empreendedores que querem criar e desenvolver os seus negócios (Karlsson, 2005).

Mais recentemente Pichler e Wallace (2007) distinguem o capital social formal do capital social informal. Definem o capital social formal como aquele que envolve a participação formal em organizações, nomeadamente organizações civis (Schofer \& Fourcade-Gourinchas, 2001), enquanto o capital informal é aquele que surge das relações socais que os indivíduos estabelecem com a família, amigos, colegas, vizinhos, etc. Pichler e Wallace (2007) entendem que estas duas dimensões do capital social estão relacionadas entre si por acumulação ou substituição que difere conforme os países. Na europa, por exemplo, os países Nórdicos revelam níveis elevados, quer de capital social formal, que informal, enquanto os países do sul parecem compensar níveis mais baixos de capital social formal com níveis elevados de capital social informal.

Vários estudos sugerem que o capital humano (ao nível da educação) está positivamente correlacionado com o capital social formal (Bekkers, 2005; Gesthuizen, 2006). Contudo, alguns estudos encontraram uma correlação negativa entre capital humano e as relações familiares, mas o mesmo não verificaram com os amigos (Kaariainene \& Lehtonen, 2006; Scheepers, Grotenhuis, \& Gelissen, 2002). No entanto, outros estudos verificaram que as pessoas com níveis de educação mais elevados 
tendem a desenvolver contactos mais frequentes quer com a família, quer com amigos (Van Oorschot \& Arts, 2005). Estas evidências dos diferentes efeitos do capital social formal e informal parecem indicar uma necessidade de se analisar estas duas componentes do capital social no empreendedorismo.

\subsection{Redes sociais empreendedoras e acesso a recursos em diferentes fases do processo empreendedor}

Vários estudos sobre redes sociais empreendedoras evidenciam o seu papel na mobilização de recursos. De acordo com Ducci e Teixeira (2011) as redes sociais empreendedoras são relacionadas de forma positiva com o desempenho da organização, mais especificamente com o início de um novo negócio, sua continuidade e crescimento. Birley e Cromie (1988) consideram que a teoria da rede social baseia-se em dois princípios: 1) 0 processo empreendedor envolve um conjunto de recursos escassos do ambiente; 2) Os recursos são frequentemente obtidos através da rede pessoal dos empreendedores. A criação de novos negócios depende da capacidade dos empreendedores em identificarem nichos de oportunidades e conseguirem os recursos necessários. Para estes autores, durante este processo os empreendedores necessitam de informação, capital, capacidades, entre outros recursos. Alguns destes recursos são detidos pelos próprios empreendedores, outros são complementados através da sua rede social, nomeadamente através de amigos, familiares, colegas de trabalho e com outras pessoas fora de seu círculo de convivência social (Manolova, Manev, Carter, \& Gyoshev, 2006).

Outros autores como Johannisson (1998) referem a importância desta rede na obtenção não somente de recursos económicos ou financeiros (nomeadamente capital próprio, capital de familiares e amigos, linhas de crédito bancário, linhas de fomento, apoios comunitários ou capital de risco) na fase inicial do negócio, mas também de recursos não económicos relevantes para a obtenção de suporte no que concerne à ideia do negócio (nomeadamente conselhos, e informações, e apoio social e emocional) para a constituição do empreendimento. Alguns estudos evidenciam mesmo a importância das capacidades cognitivas e de capacidade de estratégia dos empresários e das suas equipas de gestão para a previsão de configurações alternativas de recursos internos e externos que permitem a empresas continuar a criar e a explorar oportunidades (Narayanan, Colwell, \& Douglas, 2009; Pandza \& Thorpe, 2009).

Assim, existem vários estudos sobre redes sociais empreendedoras que evidenciam o seu papel importante no processo empreendedor no estabelecimento e gestão de um novo negócio (Greve \& Salaff, 2003; Johannisson, 1998; Li, Wang, Huang, \& Bai, 2013).

Apesar dos vários contributos que evidenciam a importância das redes empreendedoras quer na fase de criação, quer na fase de desenvolvimento dos empreendimentos, alguns autores referem que o processo de mobilizar a rede social para aceder a recursos é dinâmica e varia ao longo do desenvolvimento do negócio (Lockett, Thompson, \& Morgenstern, 2009; Lockett \& Wild, 2014).

Deste modo, de forma a se compreender os recursos mobilizados nas diferentes fases do processo empreendedor, e de acordo com os estudos apresentados, neste artigo considera-se importante distinguir duas fases: a fase de criação e a de desenvolvimento de novos negócios.

\section{Metodologia}

Face à natureza do presente estudo, predominantemente qualitativo, e tendo em conta os objetivos propostos, procedeu-se à utilização de um conjunto de técnicas usuais nas Ciências Sociais. Trata-se de uma metodologia qualitativa, com enfoque no estudo de casos múltiplos. Esta opção prende-se com a necessidade de se compreender o fenómeno como um todo, com um grau de profundidade elevado. De acordo com Yin (2005, p. 32), o estudo de caso "é uma investigação empírica que investiga um fenómeno contemporâneo dentro do seu contexto da vida real, especialmente quando os limites entre o fenómeno e o contexto não estão claramente definidos". Yin (2009) refere ainda que um estudo de caso pode focar tanto um caso único quanto casos múltiplos. Neste trabalho será realizado o estudo de casos múltiplos em empreendimentos de Turismo em Espaço Rural.

Aquando do delineamento da metodologia foram selecionadas técnicas de investigação, tendo em conta as que mais se adequam à realidade do estudo, incidindo estas no recurso à análise documental. Esta análise documental foi feita com base numa pesquisa bibliográfica e na sua análise sobre a problemática em questão. Para além da análise documental procedeu-se à elaboração de entrevistas semiestruturadas. Uma vez que a entrevista constitui uma das técnicas de recolha de dados mais importantes que permite grande flexibilidade e muito adequada a um estudo de caso (Yin, 2005), optou-se pela realização de entrevistas, semiestruturadas diretas, dirigidas a um conjunto de stakeholders (nove entidades) ligados à atividade empreendedora do Turismo em Espaço Rural (Quadro 1) e aos empreendedores de doze empreendimentos de Turismo em Espaço Rural, seis no Brasil e seis em Portugal (Quadro 2).

\section{Quadro 1 - Entidades/organismos entrevistados}

\begin{tabular}{|l|c|}
\hline \multicolumn{1}{|c|}{\begin{tabular}{l} 
Entidades/Organismos \\
\hline
\end{tabular}} & Entrevistado \\
\hline IDESTUR-Instituto de Desenvolvimento de Turismo Rural & Presidente \\
\hline Associação Café com Leite & Presidente \\
\hline Associação de Fazendas Históricas Paulistas & Associado \\
\hline COMTUR de Socorro & Presidente \\
\hline Associação ATURP & Presidente \\
\hline Entidade Regional de Turismo da Região de Lisboa & Representante da ERT- RL \\
\hline ADREPES-Associação para o Desenvolvimento Rural da Península de Setúbal & Coordenadora \\
\hline Conselho consultivo para o desenvolvimento do turismo do concelho Mafra (CMTM) & Representante \\
\hline Câmara Municipal de Palmela & Representante da Câmara Municipal de Palmela na \\
\hline
\end{tabular}

Fonte: Elaboração das autoras 


\begin{tabular}{|l|l|l|l|l|}
\hline \multicolumn{1}{|c|}{ Quadro 2 - Casos de Turismo Rural em estudo } \\
\hline \multicolumn{1}{|c|}{ Empreendimento TER } & Entrevistado & País & Região & Localização \\
\hline Fazenda Buracão & Proprietário & Brasil & São Paulo & Mucoca \\
\hline Fazenda Nova & Proprietário & Brasil & São Paulo & Sucoca \\
\hline Hotel Fazenda Parque dos Sonhos & Proprietário & Brasil & São Paulo & Socorro \\
\hline Sabores do Currupia & Proprietárias & Brasil & São Paulo \\
\hline Fazenda Vista Alegre & Proprietária & Brasil & São Paulo & Ribeirão Preto/Sertãozinho \\
\hline Estância Fazendinha & Proprietária & Brasil & São Paulo & Ribeirão Preto \\
\hline Herdade Moinho Novo & Proprietário & Portugal & Lisboa & Montijo/Canha \\
\hline Quinta do Alcube & Proprietário & Portugal & Lisboa & Setúbal/Azeitão \\
\hline Quinta dos Mochos & Proprietário & Portugal & Lisboa & Montijo/Pegões \\
\hline Aldeia da Mata Pequena & Proprietário & Portugal & Lisboa & Mafra/Aldeia da Mata Pequena \\
\hline Quinta do Miguel & Proprietária & Portugal & Lisboa & Sesimbra/Praia do Meco \\
\hline Quinta da Marcahanta & Proprietária & Portugal & Santarém (Antiga Região LVT) & Cartaxo \\
\hline
\end{tabular}

Os dados recolhidos através das entrevistas diretas foram corroborados com um conjunto de outras evidências, nomeadamente a análise de documentos (textos e folders elaborados pelos empreendedores, informação institucional disponibilizada pelos empreendedores e outra disponível na internet, matérias publicadas na comunicação social, nomeadamente reportagens, artigos de divulgação em jornais, revistas da especialidade e internet), a observação de artefactos físicos (instalações físicas dos empreendimentos e funcionamento in loco). Assim, foram também adotadas a observação direta e a participante como fonte de evidências neste estudo de caso. Os dados foram recolhidos no Brasil durante o mês de Setembro de 2014 e em Portugal durante os meses de Outubro de 2014 e de Janeiro de 2015.

Relativamente à amostra, trata-se de uma amostra não probabilística propositada heterogénea. Segundo Saunders, Lewis e Thornhill (2012), neste tipo de amostragem o investigador utiliza o seu julgamento para selecionar os casos que melhor se adaptem a responder às questões da pesquisa e que melhor respondem aos objetivos propostos pela investigação, sendo frequentemente utilizado em amostras muito pequenas, como nos estudos de caso. Sendo uma amostra heterogénea, foram selecionados participantes com características suficientemente diversas, de forma a permitir a maior variação possível nos dados recolhidos. A amostra incluirá casos de Turismo em Espaço Rural em Portugal no Brasil.

De forma a responder à questão de partida "Existe uma relação virtuosa entre capital social e empreendedorismo rural?" e tendo em conta o objetivo principal e objetivos específicos deste estudo foram definidas um conjunto de categorias analíticas, com base na revisão de literatura desenvolvida:

1. Tipos de redes sociais (formais e informais) usadas nas várias fases do processo empreendedor (Pichler \& Wallace, 2007);
2. Recursos económicos e não económicos acedidos pelos empreendedores (Greve \& Salaff, 2003; Johannisson, 1998; Manolova et al., 2006; Narayanan et al., 2009; Pandza \& Thorpe, 2009).

3. Dimensões do capital social (aspetos estruturais, relacionais e cognitivos) que facilitaram o acesso aos diferentes tipos de recursos (Nahapiet \& Ghoshal, 1998).

Para efetuar o tratamento da análise da informação recolhida procedeu-se à análise estrutural de conteúdo, do tipo categorial, o que permitiu reconstruir os diferentes quadros de perceção que pretendem esclarecer a relação entre capital social e a criação e desenvolvimento do empreendedorismo em Turismo em Espaço Rural, considerando as categorias previamente apesentadas.

\section{Estudo empírico}

4.1 A atividade empreendedora, dinamização das economias locais e relevância do capital social: uma perceção dos stakeholders

Dada a importância do Turismo em Espaço Rural para as economias locais, dinamizada pela atividade empreendedora, considerou-se relevante numa primeira parte do estudo empírico proceder a uma auscultação junto de alguns stakeholders muito diretamente envolvidos com o desenvolvimento deste tipo de turismo em ambos os países, no sentido de se compreender, não somente o reconhecimento da importância desta atividade por parte destes, mas também da relevância do capital social para o sucesso da mesma. Assim, foram colocadas as seguintes perguntas abertas: 1) Qual a importância da atividade empreendedora TER para as economias locais e 2) Quais os aspetos mais relevantes relacionados com o capital social para o sucesso da atividade empreendedora TER. O quadro 3 apresenta um resumo das respostas recolhidas através da auscultação às entidades entrevistadas. 


\section{Quadro 3 - Entidades entrevistas e síntese das respostas obtidas referente à importância do Turismo em Espaço Rural}

\section{Entidades/Organismos}

Q1. Atividade empreendedora TER e importância para as economias locais

Q2. Aspetos mais relevantes relacionados com o capital social para o sucesso da atividade empreendedora TER

O TER contribui para a promoção ambiental, histórica e cultural das regiões, pode desenvolver a realidade sem desfazer uma identidade, pode desenvolver uma realidade colaborativa com intervenção de vários atores

Desenvolvimento de Turismo Rural

O TER promove o desenvolvimento rural, valoriza a produção da região, agrega valor à produção agropecuária, promove a cultura gastronómica, o modo de vida das regiões

Associação Café com Leite

O TER contribuiu para o entendimento e reconhecimento da realidade diferenciada e particular destes Associação de Fazendas Históricas Paulistas empreendimentos brasileiros, no que concerne preservação da identidade histórica, patrimonial e cultural das regiões

O TER promove o desenvolvimento rural, promove e dá a conhecer as regiões, revitaliza as infraestruturas de apoio, contribui para a qualidade de vida das populações, cria sinergias e gera riqueza

O TER revitaliza as regiões, permite manter explorações agrícolas e contribuir para o aumento de renda, contribu para uma ligação à terra e a tradições, culturas e hábitos já esquecidos

O TER é importante no contexto das economias rurais. Não apenas porque representa um complemento à "tradicional" economia de base agrícola como assume investimentos em contraciclo com a (aparente) irreversível concentração urbana

O TER pode contribuir para o desenvolvimento da ADREPES-Associação para o agricultura familiar e dos pequenos agricultores, na Desenvolvimento Rural da melhoria dos meios de subsistência, na gestão dos Península de Setúbal $\quad$ recursos naturais, na proteção do meio ambiente e na promoção do desenvolvimento das zonas rurais

O TER pode contribuir para a revitalização e preservação cultural, patrimonial, arquitetónico, para a manutenção das tradições e hábitos de vida e preservação de saberes e fazeres. Contribui para o aumento da notoriedade das regiões através da preservação da sua identidade, garantindo a sustentabilidade das mesmas

Nas regiões onde a oferta turística tem alguma consistência e dimensão capaz de atrair fluxo turístico significativo e motivar a procura, o TER poderá ser uma vertente interessante da atividade turística e se assim conseguir ter impactos positivos nas economia rurais. Se o proprietário ou empreendedor for capaz de integrar a sua oferta na oferta da restauração ou das experiências enoturísticas, e se for capaz de diferenciar o seu estabelecimento o seu contributo será relevante

Fonte: Elaboração das autoras.
Fundamentais os recursos endógenos da região, parcerias colaborativas

Salienta-se os recursos naturais, atividades agrícolas, infraestruturas apropriadas, conhecimento técnico, contactos pessoais, parceiros colaborativos, recursos económicos próprios

Muito importante a existência de recursos naturais, históricos, arquitetónicos, infraestruturas apropriadas, conhecimento técnico, contactos pessoais, organismos institucionais, recursos econômicos próprios, programas do Estado

Considera muito importante a presença de recurso naturais, infraestruturas apropriadas, conhecimento técnico, contactos pessoais, capacidade empreendedora, parceiros colaborativos, comunidade envolvida, organismos institucionais não financeiros, recursos econômicos próprios, programas do Estado

Destaca os recursos naturais, atividades agrícolas, infraestruturas apropriadas, conhecimento técnico, contactos pessoais, parceiros colaborativos, organismos institucionais não financeiros, recursos econômicos próprios

O investimento em rede na venda e na comercialização das ofertas TER. Este tem sido o fator crítico de sucesso na viabilidade de pequenos investimentos na área do alojamento no espaço rural

São essenciais os recursos naturais, atividades agrícolas, capacidade empreendedora, organismos institucionais

São fundamentais os recursos naturais, históricos, arquitetónicos, infraestruturas apropriadas, conhecimento técnico, contactos pessoais, organismos institucionais financeiros e não financeiros, recursos econômicos próprios

A ligação à comunidade, aos outros agentes econômicos e a capacidade de estabelecer comunicação com os seus potenciais públicos-alvo serão determinantes para o sucesso do seu negócio. Os recursos mais relevantes serão a qualidade e autenticidade (que garante a diferenciação), as competências para a promoção digital e a utilização das novas tecnologias (capaz de aproximar o longínquo), a existência na região de uma parceria entre agentes da atividade turística, assim como a existência de produtos locais de qualidade com notoriedade suficiente para motivar a visita

\subsection{A análise dos casos de Turismo em Espaço Rural}

De acordo com as categorias analíticas definidas e apresentadas previamente foi realizada uma análise às respostas das entrevistas realizadas nos empreendimentos de Turismo em Espaço Rural no Brasil e em Portugal. Apresenta-se de seguida um resumo sistematizado desta análise de acordo com as categorias analíticas pré-definidas na metodologia: 1 ) os tipos de redes sociais (formais e informais) (Quadros 4 e 5); 2) os recursos económicos (capital próprio, capital de familiares e amigos, linhas de crédito bancário, linhas de fomento, apoios comunitários ou capital de risco) e não económicos (conselhos, e informações, e apoio social e emocional) acedidos pelos empreendedores (quadros 4 e 5); e 3) as dimensões do capital social que facilitaram o acesso aos diferentes tipos de recursos, quer na fase de criação, quer na fase de desenvolvimento dos empreendimentos (Quadros 6 e 7). 
Quadro 4 - Tipo de redes sociais e recursos económicos e não económicos acedidos pelos empreendedores TER (Brasil)

\begin{tabular}{|c|c|c|c|c|c|}
\hline TER & Fases & $\begin{array}{l}\text { Tipos de } \\
\text { redes sociais }\end{array}$ & Descrição das redes & $\begin{array}{l}\text { Recursos } \\
\text { económicos }\end{array}$ & $\begin{array}{l}\text { Recursos não } \\
\text { Económicos }\end{array}$ \\
\hline \multirow{4}{*}{$\begin{array}{l}\text { Fazenda } \\
\text { Buracão }\end{array}$} & \multirow{2}{*}{ Criação } & Informais & Família & \multicolumn{2}{|c|}{ Acedidos através da rede informal } \\
\hline & & Formais & SEBRAE, Associação Café com Leite & & $\begin{array}{l}\text { Acedidos através } \\
\text { da rede formal }\end{array}$ \\
\hline & \multirow[b]{2}{*}{ Desenvolvimento } & Informais & Família & \multicolumn{2}{|c|}{ Acedidos através da rede informal } \\
\hline & & Formais & $\begin{array}{l}\text { SEBRAE, Associação Café com Leite, SENAR - } \\
\text { Serviço Nacional de Aprendizagem Rural, } \\
\text { Município }\end{array}$ & & $\begin{array}{l}\text { Acedidos através } \\
\text { da rede formal }\end{array}$ \\
\hline \multirow{5}{*}{ Fazenda Nova } & \multirow{3}{*}{ Criação } & Informais & Família & $\begin{array}{l}\text { Acedidos através } \\
\text { da rede informal }\end{array}$ & \multirow{2}{*}{$\begin{array}{l}\text { Acedidos através } \\
\text { da rede informal }\end{array}$} \\
\hline & & & Amigos & & \\
\hline & & Formais & $\begin{array}{l}\text { Contactos profissionais desenvolvidos na sua } \\
\text { atividade de editor, principalmente dos meios } \\
\text { de comunicação }\end{array}$ & & $\begin{array}{l}\text { Acedidos através } \\
\text { da rede formal }\end{array}$ \\
\hline & \multirow{2}{*}{ Desenvolvimento } & Informais & Família & \multicolumn{2}{|c|}{ Acedidos através da rede informal } \\
\hline & & Formais & $\begin{array}{l}\text { TV Globo, Jornal Estado de São Paulo, SENAC, } \\
\text { Ministério do Turismo Secretaria da Cultura }\end{array}$ & & $\begin{array}{l}\text { Acedidos através } \\
\text { da rede formal }\end{array}$ \\
\hline \multirow{5}{*}{$\begin{array}{l}\text { Hotel Fazenda } \\
\text { Campo dos } \\
\text { Sonhos }\end{array}$} & \multirow{3}{*}{ Criação } & Informais & Família & $\begin{array}{l}\text { Acedidos através } \\
\text { da rede informal }\end{array}$ & \multirow{2}{*}{$\begin{array}{l}\text { Acedidos através } \\
\text { da rede informal }\end{array}$} \\
\hline & & & Amigos/colegas & & \\
\hline & & Formais & $\begin{array}{l}\text { Contactos profissionais, de agentes sociais e } \\
\text { económicos do turismo e da comunidade em } \\
\text { geral }\end{array}$ & & $\begin{array}{l}\text { Acedidos através } \\
\text { da rede formal }\end{array}$ \\
\hline & \multirow[b]{2}{*}{ Desenvolvimento } & Informais & Família & & $\begin{array}{l}\text { Acedidos através } \\
\text { da rede informal }\end{array}$ \\
\hline & & Formais & $\begin{array}{l}\text { COMTUR, AC, Prefeitura, FACEP, SEBRAE, } \\
\text { SENAC, SENAI, ABETA, ABRATUR, ABIH, e ABAV, } \\
\text { Media (TV e de revistas especializadas, Guia } 4 \\
\text { Rodas e a Revista Guia Guia Turista) }\end{array}$ & & $\begin{array}{l}\text { Acedidos através } \\
\text { da rede formal }\end{array}$ \\
\hline \multirow{2}{*}{$\begin{array}{l}\text { Sabores do } \\
\text { Currupia }\end{array}$} & \multirow{2}{*}{ Criação } & Informais & Família, colegas, amigos & \multicolumn{2}{|c|}{ Acedidos através da rede informal } \\
\hline & & Formais & SENAE, Sindicato Rural & & $\begin{array}{l}\text { Acedidos através } \\
\text { da rede formal }\end{array}$ \\
\hline \multirow{4}{*}{$\begin{array}{l}\text { Fazenda Vista } \\
\text { Alegre }\end{array}$} & \multirow{2}{*}{ Criação } & Informais & Família, colegas & \multicolumn{2}{|c|}{ Acedidos através da rede informal } \\
\hline & & Formais & $\begin{array}{l}\text { O SEBRAE, o SENAE e a Associação de Turismo } \\
\text { Rural de Ribeirão Preto - ATURP }\end{array}$ & & $\begin{array}{l}\text { Acedidos através } \\
\text { da rede formal }\end{array}$ \\
\hline & \multirow[b]{2}{*}{ Desenvolvimento } & Informais & Família & \multicolumn{2}{|c|}{ Acedidos através da rede informal } \\
\hline & & Formais & $\begin{array}{l}\text { O SEBRAE, o SENAE e a Associação de Turismo } \\
\text { Rural de Ribeirão Preto - ATURP, AGRISHOW, } \\
\text { FENASUCRO }\end{array}$ & & $\begin{array}{l}\text { Acedidos através } \\
\text { da rede formal }\end{array}$ \\
\hline \multirow{4}{*}{$\begin{array}{l}\text { Estância } \\
\text { Fazendinha }\end{array}$} & \multirow{2}{*}{ Criação } & Informais & Família, amigos, colegas/colaboradores & \multicolumn{2}{|c|}{ Acedidos através da rede informal } \\
\hline & & Formais & $\begin{array}{l}\text { O SEBRAE e a Associação de Turismo Rural de } \\
\text { Ribeirão Preto - ATURP }\end{array}$ & & $\begin{array}{l}\text { Acedidos através } \\
\text { da rede formal }\end{array}$ \\
\hline & \multirow{2}{*}{ Desenvolvimento } & Informais & Família, amigos, colegas/colaboradores & \multicolumn{2}{|c|}{ Acedidos através da rede informal } \\
\hline & & Formais & $\begin{array}{l}\text { O SEBRAE e a Associação de Turismo Rural de } \\
\text { Ribeirão Preto - ATURP }\end{array}$ & & $\begin{array}{l}\text { Acedidos através } \\
\text { da rede formal }\end{array}$ \\
\hline
\end{tabular}


Quadro 5 - Tipo de redes sociais e recursos económicos e não económicos acedidos pelos empreendedores TER (Portugal)

\begin{tabular}{|c|c|c|c|}
\hline TER & Fases & $\begin{array}{l}\text { Tipos de } \\
\text { redes sociais }\end{array}$ & Descrição das redes \\
\hline \multirow{4}{*}{$\begin{array}{l}\text { Quinta do } \\
\text { Alcube }\end{array}$} & \multirow[b]{2}{*}{ Fase de criação } & Informais & Família \\
\hline & & Formais & $\begin{array}{l}\text { Ministério da Agricultura e do Mar e Comunidade } \\
\text { Europeia (PRODER), ADREPES, Câmara Municipal de } \\
\text { Setúbal, Câmara Municipal de Palmela, Faculdade de } \\
\text { Belas Artes, Agências de Viagem }\end{array}$ \\
\hline & \multirow[b]{2}{*}{$\begin{array}{c}\text { Fase de } \\
\text { desenvolvimento }\end{array}$} & Informais & Família \\
\hline & & Formais & $\begin{array}{l}\text { Ministério da Agricultura e do Mar e Comunidade } \\
\text { Europeia (PRODER), ADREPES, Câmara Municipal de } \\
\text { Setúbal, Câmara Municipal de Palmela, Faculdade de } \\
\text { Belas Artes, Agências de Viagem }\end{array}$ \\
\hline \multirow{4}{*}{$\begin{array}{c}\text { Quinta dos } \\
\text { Mochos }\end{array}$} & \multirow[b]{2}{*}{ Fase de criação } & Informais & Família e amigos, vizinhos \\
\hline & & Formais & $\begin{array}{l}\text { GERA, Crédito Agrícola do Montijo, Ministério da } \\
\text { Agricultura e do Mar e Comunidade Europeia (PRODER), } \\
\text { ADREPES, Câmara Municipal do Montijo, Junta de } \\
\text { freguesia de Pegões }\end{array}$ \\
\hline & \multirow[b]{2}{*}{$\begin{array}{c}\text { Fase de } \\
\text { desenvolvimento }\end{array}$} & Informais & Família \\
\hline & & Formais & $\begin{array}{l}\text { GERA, Crédito Agrícola do Montijo, ADREPES, Ministério } \\
\text { da Agricultura e do Mar e Comunidade Europeia } \\
\text { (PRODER), Câmara Municipal do Montijo, Junta de } \\
\text { freguesia de Pegões, SATIVA, CONSULAl, Faculdade de } \\
\text { Ciências de Lisboa, distribuidores e produtores } \\
\text { (Maviflora, Abelhoa) }\end{array}$ \\
\hline
\end{tabular}

Recursos Recursos não económicos Económicos Acedidos através da rede informal

Acedidos através da rede formal

Acedidos através da rede informal

Acedidos através da rede formal Acedidos atravé da rede informal

Acedidos através da rede formal

Acedidos através da rede informal

Acedidos através da rede formal

Acedidos através da rede informal

Fase de criação Amigos, outros proprietários TER, conhecidos ADREPES, Ministério da Agricultura e do Mar e Comunidade Europeia (PRODER), Câmara Municipal do Montijo, Junta de Freguesia de Canha, Câmara Municipal de Coruche

Herdade do Moinho Novo

Informais Amigos, outros proprietários TER, conhecidos

Fase de desenvolvimento

\begin{tabular}{|c|c|}
\hline & Fase de criação \\
\hline $\begin{array}{c}\text { Aldeia da Mata } \\
\text { Pequena }\end{array}$ & $\begin{array}{c}\text { Fase de } \\
\text { desenvolvimento }\end{array}$ \\
\hline
\end{tabular}

Informais ADREPES, Ministério da Agricultura e do Mar e Comunidade Europeia (PRODER), Câmara Municipal do Montijo, Junta de Freguesia de Canha, Câmara Municipal de Coruche

Família, amigos, colegas, conhecidos, comunidade, anciãos

Formais Burricadas, Quinta do Azinheiro, Vale Verdejante, meios de comunicação social

Informais

Família, amigos, colegas, conhecidos, comunidade, anciãos

Câmara Municipal de Mafra, Associação Burricadas, Quinta do Azinheiro e Vale Verdejante, a Escola de Surf, o Campo Cova da Baleia e a Terra Azul, meios de comunicação social

Fase de criação

Informais

Família e amigos

Quinta do

Miguel

Fase de desenvolvimento

Formais Meios de comunicação social

Informais Família, amigos

Câmara Municipal de Sesimbra, ADEPES, Ministério da Agricultura e do Mar e Comunidade Europeia (PRODER),

Formais Gabinete de Arquitetura AMA - Aires Mateus Associados e promotor de projetos de apoio a fundos europeus

Fase de criação

Informais

Família

Fase de

Quinta da

Marchanta

Acedidos através da rede formal

Acedidos através da rede informal

Acedidos através da rede formal

Acedidos através da rede informal

Acedidos através da rede formal Acedidos através da rede informal

Acedidos através da rede formal

Acedidos através da rede informal

Acedidos através da rede formal

Acedidos através da rede informal

Acedidos através da rede formal Acedidos através da rede informal Acedidos através da rede informal
Informais

Família, amigos

Formais

Câmara Municipal do Cartaxo, Tagus Natura, Coudelaria Acedidos através da rede formal 
Quadro 6 - Dimensões do capital social que facilitaram o acesso aos diferentes tipos de recursos relevantes para a criação e desenvolvimento dos empreendimentos TER (Brasil)

\begin{tabular}{|c|c|c|c|c|}
\hline \multirow[b]{2}{*}{ TER } & \multirow[b]{2}{*}{ Fases } & \multicolumn{3}{|c|}{$\begin{array}{l}\text { Aspetos das dimensões do capital social que facilitaram o acesso aos diferentes tipos de recursos } \\
\text { de acordo com as diferentes dimensões }\end{array}$} \\
\hline & & Dimensão Estrutural & Dimensão Relacional & Dimensão Cognitiva \\
\hline $\begin{array}{l}\text { Fazenda } \\
\text { Buracão }\end{array}$ & Criação e Desenvolvimento & $\begin{array}{l}\text { Localização, configuração } \\
\text { simples, familiar, poucas } \\
\text { relações de hierarquia, aspetos } \\
\text { físicos e ambientais }\end{array}$ & $\begin{array}{l}\text { Confiança, respeito, o dever e } \\
\text { obrigações para com a família, } \\
\text { identificação do grupo em relação } \\
\text { ao projeto, motivação, segurança e } \\
\text { partilha }\end{array}$ & $\begin{array}{l}\text { Linguagem e códigos comuns } \\
\text { decorrentes dos valores } \\
\text { familiares e da formação } \\
\text { comum entre dois dos } \\
\text { empreendedores }\end{array}$ \\
\hline Fazenda Nova & Criação e Desenvolvimento & $\begin{array}{l}\text { Localização, configuração } \\
\text { familiar, aspetos físicos, } \\
\text { históricos, culturais e } \\
\text { ambientais }\end{array}$ & $\begin{array}{l}\text { Confiança, preservação da herança } \\
\text { histórica e familiar, forte } \\
\text { identificação e partilha }\end{array}$ & $\begin{array}{l}\text { Linguagem e códigos comuns } \\
\text { que resultam dos laços } \\
\text { familiares, de amigos e } \\
\text { contactos pessoais e do } \\
\text { conhecimento entre os vários } \\
\text { elementos, assim como da } \\
\text { formação na área cultural e } \\
\text { social do proprietário e de suas } \\
\text { filhas }\end{array}$ \\
\hline \multirow[b]{2}{*}{$\begin{array}{l}\text { Hotel } \\
\text { Fazenda } \\
\text { Campo dos } \\
\text { Sonhos }\end{array}$} & Criação & $\begin{array}{l}\text { Localização, } \\
\text { simples e familiguração } \\
\text { funcionamento em rede, gestão } \\
\text { e exploração do negócio muito } \\
\text { centrada na figura do } \\
\text { empreendedor, reduzido } \\
\text { número de infraestruturas } \\
\text { (apenas o lago) }\end{array}$ & $\begin{array}{l}\text { Cooperação, confiança, pressão e a } \\
\text { resiliência, proatividade, } \\
\text { solidariedade social, preocupação } \\
\text { educacional, cultural e ambiental }\end{array}$ & $\begin{array}{l}\text { Linguagem e códigos comuns } \\
\text { que resultam dos laços com a } \\
\text { comunidade, formação do } \\
\text { empreendedor, sua } \\
\text { experiência foram } \\
\text { importantes na criação do } \\
\text { projeto }\end{array}$ \\
\hline & Desenvolvimento & $\begin{array}{l}\text { Localização permitiu um } \\
\text { crescimento do negócio em } \\
\text { várias vertentes, a configuração } \\
\text { deixou de ser tão simples, } \\
\text { aumento dos recursos } \\
\text { humanos, maior hierarquização } \\
\text { e definição de funções, } \\
\text { continuação do funcionamento } \\
\text { em rede, gestão e exploração } \\
\text { do negócio muito centrada na } \\
\text { figura do empreendedor, } \\
\text { construção de elevado número } \\
\text { de infraestruturas }\end{array}$ & $\begin{array}{l}\text { Cooperação, confiança, pressão e a } \\
\text { resiliência, proatividade, } \\
\text { solidariedade social, preocupação } \\
\text { educacional, cultural e ambiental, } \\
\text { procura de soluções conjuntas e } \\
\text { não individuais, sentido de dever e } \\
\text { de obrigação do empreendedor em } \\
\text { relação em comunidade e vice- } \\
\text { versa, pressão a um conjunto de } \\
\text { normas que pretendem manter o } \\
\text { associativismo }\end{array}$ & $\begin{array}{l}\text { Linguagem e códigos comuns } \\
\text { que resultam dos laços com a } \\
\text { comunidade, formação do } \\
\text { empreendedor, sua } \\
\text { experiência parecem terem } \\
\text { sido importantes, no } \\
\text { desenvolvimento da } \\
\text { legitimidade e da promoção de } \\
\text { uma cultura empreendedora }\end{array}$ \\
\hline $\begin{array}{l}\text { Sabores do } \\
\text { Currupia }\end{array}$ & Criação & $\begin{array}{l}\text { Localização, infraestrutura rural } \\
\text { já existente um cariz muito } \\
\text { simples e familiar, sem } \\
\text { hierarquização, recursos rurais } \\
\text { que proporcionam experiências } \\
\text { genuínas }\end{array}$ & $\begin{array}{l}\text { Confiança, trabalho cooperativo, } \\
\text { motivação, solidariedade }\end{array}$ & $\begin{array}{l}\text { Linguagem e códigos comuns } \\
\text { decorrentes da ruralidade da } \\
\text { comunidade e falta de } \\
\text { identificação com o projeto } \\
\text { empresarial, quer por parte da } \\
\text { empreendedora, quer por } \\
\text { parte da comunidade }\end{array}$ \\
\hline $\begin{array}{l}\text { Fazenda Vista } \\
\text { Alegre }\end{array}$ & Criação e Desenvolvimento & $\begin{array}{l}\text { Localização e infraestrutura já } \\
\text { existente (fazenda da família), } \\
\text { configuração familiar simples, } \\
\text { uma dimensão razoável e uma } \\
\text { divisão de funções clara, } \\
\text { razoável utilização de recursos } \\
\text { humano, forte presença de } \\
\text { aspetos físicos, ambientais e } \\
\text { rurais }\end{array}$ & $\begin{array}{l}\text { Confiança reciproca, entre os } \\
\text { empreendedores e os seus } \\
\text { familiares, a solidariedade e o } \\
\text { espírito cooperativo, partilha de } \\
\text { recursos }\end{array}$ & $\begin{array}{l}\text { Linguagem e códigos comuns } \\
\text { decorrentes dos valores } \\
\text { familiares e da formação da } \\
\text { empreendedora (área da } \\
\text { educação) que conferiram } \\
\text { skills e competências para a } \\
\text { implementação do projeto e } \\
\text { seu reconhecimento e } \\
\text { legitimidade }\end{array}$ \\
\hline \multirow[b]{2}{*}{$\begin{array}{l}\text { Estância } \\
\text { Fazendinha }\end{array}$} & Criação & $\begin{array}{l}\text { Infraestrutura nova, construída, } \\
\text { configuração familiar, aspetos } \\
\text { naturais relevantes }\end{array}$ & $\begin{array}{l}\text { Confiança reciproca, entre a } \\
\text { empreendedora e os seus } \\
\text { familiares, apoio e motivação dos } \\
\text { amigos }\end{array}$ & $\begin{array}{l}\text { Linguagem e códigos comuns } \\
\text { decorrentes } \\
\text { predominantemente dos } \\
\text { valores familiares }\end{array}$ \\
\hline & Desenvolvimento & $\begin{array}{l}\text { Crescimento gradual da } \\
\text { construção da infraestrutura, } \\
\text { localização privilegiada, } \\
\text { aumento de infraestruturas e } \\
\text { de atividades com recurso ao } \\
\text { rio, configuração familiar, } \\
\text { utilização crescente de recursos } \\
\text { humanos, divisão de funções, } \\
\text { existência de aspetos naturais } \\
\text { relevantes }\end{array}$ & $\begin{array}{l}\text { Confiança, entreajuda, amizade } \\
\text { entre os colaboradores da } \\
\text { Fazendinha e os seus proprietários } \\
\text { e familiares }\end{array}$ & $\begin{array}{l}\text { Linguagem e códigos comuns } \\
\text { decorrentes dos valores } \\
\text { familiares e da formação e } \\
\text { competências dos vários } \\
\text { familiares que trabalham no } \\
\text { empreendimento, aumento da } \\
\text { dimensão empresarial do } \\
\text { projeto e da credibilidade e } \\
\text { legitimidade junto de uma } \\
\text { comunidade alargada }\end{array}$ \\
\hline
\end{tabular}


Quadro 7 - Dimensões do capital social que facilitaram o acesso aos diferentes tipos de recursos relevantes para a criação e desenvolvimento dos empreendimentos TER (Portugal)

\begin{tabular}{|c|c|c|c|c|}
\hline \multirow[b]{2}{*}{ TER } & \multirow[b]{2}{*}{ Fases } & \multicolumn{3}{|c|}{$\begin{array}{l}\text { Aspetos das dimensões do capital social que facilitaram o acesso aos diferentes tipos de recursos de } \\
\text { acordo com as diferentes dimensões }\end{array}$} \\
\hline & & Dimensão Estrutural & Dimensão Relacional & Dimensão Cognitiva \\
\hline Quinta do Alcube & $\begin{array}{ll}\text { Criação } & \text { e } \\
\text { Desenvolvimento }\end{array}$ & $\begin{array}{l}\text { Localização, configuração familiar, } \\
\text { existência de aspetos físicos e } \\
\text { ambientais que viabilizaram o } \\
\text { projeto de produção de vinho, } \\
\text { enoturismo, agroturismo e museus } \\
\text { reabilitados de espaços já } \\
\text { existentes }\end{array}$ & $\begin{array}{l}\text { Confiança, o respeito, o desejo de } \\
\text { manter o património familiar, valores } \\
\text { de sustentabilidade cultural e } \\
\text { ambiental }\end{array}$ & $\begin{array}{l}\text { Partilha ao nível da linguagem e de } \\
\text { códigos, resultante não só dos laços } \\
\text { familiares e da relação entre os vários } \\
\text { elementos, mas também devido } \\
\text { formação e gosto pela prática agrícola } \\
\text { do atual proprietário }\end{array}$ \\
\hline \multirow[b]{2}{*}{$\begin{array}{l}\text { Quinta dos } \\
\text { Mochos }\end{array}$} & Criação & \multirow{2}{*}{$\begin{array}{l}\text { Projeto familiar criado de raiz, cuja } \\
\text { localização e dimensão permitiu o } \\
\text { conceito de ecossistema } \\
\text { multifacetado, as infraestruturas } \\
\text { foram sendo redimensionadas } \\
\text { consoante o crescimento e } \\
\text { diversidade do projeto }\end{array}$} & \multirow{2}{*}{$\begin{array}{l}\text { Confiança, a resiliência, o respeito } \\
\text { pelo trabalho, disciplina, a grande } \\
\text { identificação com a figura do avô, } \\
\text { exemplo de profissionalismo, de } \\
\text { competência e de rigor }\end{array}$} & $\begin{array}{l}\text { Partilha ao nível da linguagem e de } \\
\text { códigos, resultante dos laços com a } \\
\text { família nuclear que partilham o gosto } \\
\text { por este projeto TER que se constitui } \\
\text { como um projeto de vida do casal }\end{array}$ \\
\hline & Desenvolvimento & & & $\begin{array}{l}\text { Partilha ao nível da linguagem e de } \\
\text { códigos, resultantes dos laços com a } \\
\text { família nuclear. Reconhecimento e } \\
\text { respeito da comunidade pelo trabalho } \\
\text { desenvolvido, pela reabilitação do } \\
\text { espaço, empatia pela simplicidade e } \\
\text { postura em relação ao trabalho e à terra }\end{array}$ \\
\hline $\begin{array}{l}\text { Herdade do } \\
\text { Moinho Novo }\end{array}$ & $\begin{array}{l}\text { Criação } \\
\text { Desenvolvimento }\end{array}$ & $\begin{array}{l}\text { Infraestrutura construída à medida } \\
\text { do tipo de negócio, projeto } \\
\text { individual, de portfolio, } \\
\text { configuração em rede, recurso a } \\
\text { serviços externos para } \\
\text { complementaram a sua atividade } \\
\text { principal }\end{array}$ & $\begin{array}{l}\text { Forte predisposição do } \\
\text { empreendedor para arranjar } \\
\text { parceiros para os seus projeto, não } \\
\text { tem tido apoio da família daí o seu } \\
\text { investimento em relações } \\
\text { interpessoais, grande entusiamo e } \\
\text { confiança inicial nestes parceiros que } \\
\text { nem sempre acabam bem, facilidade } \\
\text { para arranjar novos parceiros }\end{array}$ & $\begin{array}{l}\text { Formação inicial justifica o tipo de } \\
\text { negócio inicial que evolui para a } \\
\text { atividade turística. Atualização de } \\
\text { conhecimentos em áreas completares. } \\
\text { Perfil, empreendedor, com uma } \\
\text { linguagem e postura de proximidade } \\
\text { importante aos parceiros. Tem ganho } \\
\text { reconhecimento e respeito junto da } \\
\text { comunidade }\end{array}$ \\
\hline $\begin{array}{l}\text { Aldeia da Mata } \\
\text { Pequena }\end{array}$ & $\begin{array}{l}\text { Criação } \\
\text { Desenvolvimento }\end{array}$ & $\begin{array}{l}\text { Projeto suportado na reconstrução } \\
\text { e reabilitação de uma aldeia, ao } \\
\text { longo do tempo, com grande } \\
\text { envolvimento da família e dos } \\
\text { anciãos, configuração simples, } \\
\text { funcionamento familiar e pouco } \\
\text { hierarquizado, suportado no } \\
\text { desenvolvimento de relações } \\
\text { informais }\end{array}$ & $\begin{array}{l}\text { Experiências passadas relevantes de } \\
\text { infância, figura do avô que transmitiu } \\
\text { o valor da preservação da cultura, } \\
\text { história, tradição e património da } \\
\text { região, fortes relações de amizade } \\
\text { com os amigos os amigos, e colegas } \\
\text { de liceu e da universidade, } \\
\text { solidariedade dos amigos, laços } \\
\text { relacionais entre o casal que } \\
\text { partilham um projeto de vida. }\end{array}$ & $\begin{array}{l}\text { Empreendedores têm formações } \\
\text { académicas que lhes permitiram } \\
\text { adquirir um conjunto de conhecimentos } \\
\text { e competências importante, existência } \\
\text { de grande afinidade ao nível da } \\
\text { linguagem e de códigos, resultante da } \\
\text { identificação dos valores culturais e de } \\
\text { preservação da região, harmonia não } \\
\text { entre os empreendedores e entre estes } \\
\text { e a comunidade }\end{array}$ \\
\hline \multirow[b]{2}{*}{ Quinta do Miguel } & Criação & $\begin{array}{l}\text { Projeto suportado na } \\
\text { transformação e adaptação de } \\
\text { uma quinta ou espaço de lazer e de } \\
\text { férias da família. Configuração } \\
\text { simples e familiar }\end{array}$ & $\begin{array}{l}\text { Forte preocupação dos proprietários } \\
\text { pelo bem-estar dos seus clientes. Os } \\
\text { dos laços familiares e a confiança } \\
\text { mútua, a facilidade de } \\
\text { relacionamentos que contribuíram } \\
\text { para um forte suporte de grande } \\
\text { utilidade para o sucesso do projeto }\end{array}$ & \multirow{2}{*}{$\begin{array}{l}\text { Identificação com um conjunto de } \\
\text { valores relacionados com a busca da } \\
\text { harmonia com a natureza que se traduz } \\
\text { na paz e bem-estar que os proprietários } \\
\text { procuram proporcionar aos seus } \\
\text { clientes. Forte ligação com a região, } \\
\text { comunidade rural, os proprietários mas } \\
\text { aberta e recetiva }\end{array}$} \\
\hline & Desenvolvimento & $\begin{array}{l}\text { Projeto suportado na } \\
\text { transformação e adaptação de } \\
\text { uma quinta ou espaço de lazer e de } \\
\text { férias da família. Configuração } \\
\text { simples, uma equipa pequena, } \\
\text { alguma definição de funções, mas } \\
\text { polivalente e uma cultura forte e } \\
\text { bem definida. Recurso ao serviço } \\
\text { de várias empresas externas }\end{array}$ & $\begin{array}{l}\text { Forte preocupação dos proprietários } \\
\text { pelo bem-estar dos seus clientes e } \\
\text { grande confiança numa rede de } \\
\text { contatos relevantes. Laços familiares } \\
\text { enraizados na confiança mútua, } \\
\text { enfoque na obtenção de níveis de } \\
\text { qualidade e satisfação. a prestarem } \\
\text { de Este foco inspira os colaboradores } \\
\text { serviços de levada qualidade e } \\
\text { profissionalismo procurando sempre } \\
\text { uma melhoria contínua }\end{array}$ & \\
\hline $\begin{array}{l}\text { Quinta da } \\
\text { Marchanta }\end{array}$ & $\begin{array}{l}\text { Fase de criação e de } \\
\text { desenvolvimento }\end{array}$ & $\begin{array}{l}\text { Projeto de cariz muito familiar, } \\
\text { com uma configuração muito } \\
\text { simples }\end{array}$ & $\begin{array}{l}\text { A confiança e as relações familiares } \\
\text { com as pessoas que trabalham na } \\
\text { quinta predominam }\end{array}$ & $\begin{array}{l}\text { Conhecimentos adquiridos ao longo da } \\
\text { sua formação pouco relevantes, } \\
\text { necessidade de adquirir conhecimentos } \\
\text { e competências ao nível da gestão. A } \\
\text { vertente empresarial é desconhecida, } \\
\text { Forte laços de cooperação e } \\
\text { solidariedade com a comunidade que } \\
\text { considera o projeto é importante para a } \\
\text { região. }\end{array}$ \\
\hline
\end{tabular}




\section{Discussão dos resultados}

Considerando o principal objetivo deste estudo (compreender a relação entre capital social e criação e desenvolvimento de empreendimentos em Turismo em Espaço Rural) e através das informações recolhidas quer dos principais stakeholders ligados ao TER no Brasil e em Portugal, quer das informações recolhidas através dos empreendedores TER, igualmente no Brasil e em Portugal, foi possível confirmar a existência de uma relação virtuosa entre o capital social e a atividade empreendedora. Tanto stakeholders, quanto empreendedores compreendem esta relação e seu contributo para o desenvolvimento das regiões.

Assim, as entrevistas levadas a cabo junto dos organismos permitiram confirmar a importância da atividade TER para as economias locais, que dependem muito da capacidade empreendedora dos empreendedores e dos recursos que estes detêm e conseguem mobilizar. Frequentemente, esses conseguem incutir uma dinâmica e uma cultura empreendedora às comunidades envolvidas, contribuindo para a geração de riqueza, preservação do património rural, cultural e arquitetónico envolvidos, e promoção da identidade, notoriedade e desenvolvimento das regiões onde se inserem. Esta evidência parece ser reconhecida por um conjunto de stakeholders, nomeadamente associações ligadas ao turismo rural, associações de desenvolvimento regional, entidades do turismo, sendo corroborada na revisão de literatura, com referência a um conjunto de estudos (Baoren, 2011; Cristóvão, Medeiros, \& Melides, 2010; Mendonça, 2006; Meyer-Cech, 2005; Ohe \& Kurihara, 2013).

\section{Discussão}

A análise dos empreendimentos em Turismo em Espaço Rural levada a cabo indicia que o capital social informal e formal detido pelos empreendedores são determinantes na mobilização de recursos económicos (capital próprio, capital de familiares e amigos, linhas de crédito bancário, linhas de fomento, apoios comunitários ou capital de risco) e não económicos (conselhos, e informações, e apoio social e emocional). Também este aspeto é corroborado na revisão de literatura por um conjunto de autores (Birley \& Cromie, 1988; Greve \& Salaff, 2003; Johannisson, 1998; Li et al., 2013; Manolova et al., 2006; Narayanan et al., 2009; Pandza \& Thorpe, 2009).

De um modo geral, em todos os casos estudados, o capital socia informal é muito importante na mobilização de recursos não económicos, nomeadamente em termos de obtenção de motivação, de apoio, na partilha de recursos (infraestruturas, equipamentos, entre outros), na participação ativa dos projetos e no aumento de novos contactos cruciais para o desenvolvimento dos projeto. Este capital é também particularmente importante, nos casos brasileiros, na mobilização de recursos económicos. Este aspeto pode relacionar-se com aspetos económicos e culturais próprios deste país. Habituados a funcionar numa economia muito informal e engenhosos em conseguir recursos, nomeadamente económicos, sem recurso à rede formal, os empreendedores brasileiros revelam pouca dependência de organismo e instituições públicas. Nos casos portugueses, a situação é diferente. Nos casos dos empreendimentos localizados em regiões apoiadas por fundos comunitários, todos eles recorrem a estes fundos e, mesmo, para aqueles cuja localização não permite este acesso, eles recorrem à banca sem grandes dificuldades. Esta evidência parece seguir a tendência no que concerne aos níveis de capital social formal e informal na Europa. Na Europa nomeadamente nos países nórdicos, os níveis de capital socia quer formal, quer informal são elevados, enquanto os países do sul parecem compensar níveis mais baixos de capital social formal com níveis elevados de capital social informal (Pichler \& Wallace (2007). Esta tendência parece ocorrer entre o Brasil e Portugal, ou seja, no Brasil os níveis de capital social informal são elevados e em Portugal parecem existirem níveis elevados tanto de capital social formal como informal.

Apesar das diferenças no que concerne ao acesso aos recursos económicos por parte de organismos e instituições de financiamento, ou seja, apesar de nos casos brasileiros o financiamento não depender do capital social formal, enquanto nos casos portugueses, este tipo de capital parece ter um papel importante na disponibilidade de recursos, a concretização dos projetos, quer brasileiros, quer portugueses não param em consequência deste maior ou menor acesso. Nota-se, no entanto, que nos casos onde existe injeção de capital de instituições financeiras (comunitárias ou nacionais), o desenvolvimento, a modernização, sofisticação e qualidade são bastante superiores. Contudo, é transversal a todos os casos a importância dos valores associados ao projeto, quer eles sejam familiares, de preservação do ambiente, da tradição da cultura, de desenvolvimento da região para o sucesso e aceitação dos mesmos junto da comunidade, assim como a capacidade dos empreendedores desenvolverem redes sociais informais, que são determinantes para o acesso a um conjunto de recursos.

No que concerne a aspetos positivos relacionados com a gestão destas empresas, destaca-se a proximidade com os clientes e consequentemente uma flexibilidade e rapidez na resposta às suas necessidades e uma simplicidade ao nível dos processos de tomada de decisão. Geralmente estas empresas são bastantes centralizadoras na figura do(s) empreendedor(es), o que permite que as decisões sejam tomadas, nestes casos pelos próprios empreendedores, que têm uma visão global do empreendimento e valores a preservar.

Relativamente aos casos estudados, parecem existir poucas diferenças em termos de aspetos estruturais. Os empreendimentos em estudo apresentam uma configuração estrutural simples, com uma divisão de trabalho imprecisa, uma diferenciação reduzida entre níveis hierárquicos e uma coordenação realizada pela supervisão direta, que é(são) o(s) empreendedor(es). Com uma estrutura muito achatada, praticamente sem níveis hierárquicos, estas empresas desenvolvem frequentemente comportamentos pouco formalizados e na maioria dos casos, com pouco recurso ao planeamento. São pequenas empresas de cariz familiar, que recorrem muito a capitais próprios, à exceção dos projetos portugueses que se encontram localizados em regiões abrangidas pelos fundos comunitários, mas que mesmo nestes casos, os empreendedores investem também capitais próprios. Apesar de na fase de criação os empreendimento apresentarem, de uma forma geral, as caraterísticas referidas, na fase de desenvolvimento, nos casos em que o crescimento foi elevado, 
com significativo investimento em infraestruturas e recursos humanos, esta estrutura tende a tornar-se mais complexa, com maior divisão e clareza de funções, e por vezes, maior hierarquização. Esta alteração é visível em alguns empreendimentos brasileiros, nomeadamente no hotel Fazenda Parque dos Sonhos, na Fazenda Vista Alegre e na Estância Fazendinha. Nos empreendimentos portugueses, os empreendedores preferem optar por recorrer a serviços externos para complementar algumas atividades em vez de aumentar a estrutura interna.

Relativamente aos aspetos relacionais, a qualidade dos laços sociais, a duração e frequência da reciprocidade dos comportamentos, as experiências passadas e a qualidade das interações passados revelaram-se igualmente importantes em ambas as fases dos projetos estudados. No entanto, de um modo geral, os empreendedores, não só mantêm os laços sociais inicialmente existentes, como desenvolvem novos laços socias, investindo na manutenção não somente destes laços sociais passados, como também nas novas relações, o que permite um aumento da rede de contactos e uma melhor mobilização e gestão de recursos e de partilha de conhecimentos e de boas práticas à medida que os projetos se desenvolvem.

Finalmente, no que refere aos aspetos cognitivos, todos os empreendedores parecem saber aplicar e utilizar os seus conhecimentos e competências adquiridas no passado nos seus projetos. Através desta aplicação, verifica-se uma diferenciação ao nível das atividades e serviços que prestam, assim como ao nível das parcerias que desenvolvem, que geralmente, principalmente na fase inicial, dependem da rede de contactos que o empreendedor já detinha da sua experiência profissional e pessoal passada. Confirma-se, que, de um modo geral, os empreendedores vão investindo na sua formação, tentando adquirir conhecimentos nas áreas onde sentem mais necessidade. Relacionando o capital humano com o capital social formal e informal, e tendo em conta, o nível de educação dos empreendedores versus importância dos dois tipos de capital social (formal e informal) nos casos estudados, foi possível verificar que existe uma correlação positiva entre capital humano e o capital social informal, confirmando os estudos apresentados na revisão de literatura que referem que as pessoas com níveis de educação mais elevados tendem a desenvolver contatos mais frequentes quer com a família, quer com amigos (Van Oorschot \& Arts, 2005). De referir ainda, que os casos portugueses, quanto maior é o nível educacional (capital humano) maior é o capital social (formal e informal). Também esta evidência é corroborada por outros estudos que sugerem que o capital humano (ao nível da educação) está positivamente correlacionado com o capital social (Bekkers, 2005; Gesthuizen, 2006).

Por fim, à medida que os projetos crescem, nota-se uma maior identificação entre empreendedores, comunidade e entidades e agentes locais. Também a revisão da literatura evidenciava a dinâmica do processo de mobilização da rede social e do acesso a recursos com o desenvolvimento do negócio, fazendo referência a um conjunto de autores que confirmam esta variação ao longo do desenvolvimento dos empreendimentos (Lockett et al., 2009; Lockett \& Wild, 2014).
Finalmente foi possível verificar que a grande maioria dos empreendedores de Turismo em espaço Rural são motivados por benefícios relacionados com "estilo de vida", em particular em Portugal. No Brasil existe uma forte motivação pela preservação do património familiar, assim como uma forte motivação para aumentar a rendabilidade e agregar valor à atividade agrícola. Em Portugal, a motivação dos empreendedores está sempre muito ligada a um estilo ou projeto de vida que estes querem levar. Também a revisão de literatura indiciava que nos países ocidentais, uma grande parte dos empreendedores do turismo são motivados por benefícios relacionados com o "estilo de vida" e não pelo lucro (Getz \& Carlsen, 2000).

\section{Conclusões}

A revisão de literatura permitiu um enquadramento teórico sobre empreendedorismo, capital social e redes sociais empreendedoras que permitem o acesso a recursos em diferentes fases do processo empreendedor. Com uma preocupação de contextualização destas temáticas no turismo foi possível encontrar no estudo empírico resultados que corroboram os vários estudos e perspetivas apresentadas.

Deste modo, este estudo permitiu conhecer as redes sociais usadas pelos empreendedores, os recursos acedidos pelos empreendedores e os aspetos relacionados com as dimensões do capital social, que foram determinantes na mobilização dos recursos nas diferentes fases do projeto (criação e desenvolvimento), considerando as dimensões estrutural, relacional e cognitiva apresentada por Nahapiest e Goshal (1998). Vale realçar, que o foco deste estudo relaciona-se essencialmente com capital social externo e com os recursos sociais acedidos pelos empreendedores, ou seja, com a rede de relações que o empreendedor e/ou empreendimento e/ou seus colaboradores têm com stakeholders externos à empresa, quer estes sejam pessoas ou organizações.

O estudo possibilitou ainda concluir que os aspetos económicos são pois elementos chave e críticos para a criação e desenvolvimento dos projetos. Principalmente nos casos brasileiros, o acesso a esse tipo de recurso constitui uma área sensível, e, frequentemente, o empreendimento é entendido como um assunto de família e raramente recorrem a financiamento juntos de instituições bancárias ou outros organismos de financiamento.

Finalmente, foi possível concluir que, em geral, a rede informal é importante na mobilização de recursos não-económicos, sendo nos casos brasileiros, igualmente importante na mobilização de recursos económicos. Relativamente à dimensão estrutural de capital social, foi possível verificar semelhanças na fase de criação, ou seja, predominância de uma configuração simples, familiar e adoção de uma gestão informal. Constatou-se, no entanto, evidências de uma crescente complexidade em projetos com elevado crescimento durante a fase de desenvolvimento. No que respeita às dimensões relacional e cognitiva, ambas são relevantes em diferentes fases de projetos empreendedores, e à medida que esses vão crescendo e gerando mais valor, parece ocorrer uma maior identificação entre empreendedores e organizações comunitárias e agentes locais, aumentando a legitimidade do projeto e da cultura empreendedora da comunidade. 


\section{Referências}

Adler, P., \& Kwon, S. (2002). Social capital: Prospects for a new concept. Academy of Management Review, 27(1), 17-40.

Bekkers, R. (2005). Participation in voluntary associations: Relations with resources, personality and political values. Political Psychology, 26(3), 439-454. doi:10.1111/j.1467-9221.2005.00425.x

Birley, S., \& Cromie, S. (1988). Social networks and entrepreneurial in Northern Ireland. Paper presented at the Enterprise in Action Conference. Belfast, Ireland.

Burt, R. (1992). Structural holes: The social construction of competition. Cambridge, MA: Harvard University Press.

Burt, R. (2001). Structural holes versus network closure as social capital. In N. Lin, K. Cook, \& R. Burt (Eds.), Social capital: Theory and research (pp. 31-56). New Brunswick, NJ: Aldine Transaction.

Comissão Europeia. (2006). Uma política de turismo europeia renovada - Rumo a uma parceria reforçada para o turismo na Europa. Recuperado de http://eurlex.europa.eu/smartapi/cgi/sga_doc?smartapi!celexplus!prod!DocNumber\&/g=pt\&t ype_doc $=$ COMfinal\&an_doc $=2006 \&$ nu_doc $=134$

Cristóvão, A., Medeiros, V., \& Melides, R. (2010). Aldeias vinhateiras: Requalificação urbana, turismo e desenvolvimento local no Douro. PASOS: Revista de Turismo y Património Cultural, 8(4), 519-528.

Dana, L.-P., Gurau, C., \& Lasch, F. (2014). Entrepreneurship, tourism and regiona development: A tale of two villages. Entrepreneurship \& Regional Development, 26(34), 357-374. doi:10.1080/08985626.2014.918182

Davidsson, P., \& Honig, B. (2003). The role of social and human capital among nascent entrepreneurs. Journal of Business Venturing, 18(3), 301-331. doi:10.1016/S0883 9026(02)00097-6

Ducci, N. P. C., \& Teixeira, R. M. (2011). As redes sociais dos empreendedores na formação do capital social: Um estudo de casos múltiplos em municípios do norte pioneiro no estado do Paraná. Cadernos EBAPE.BR, 9(4), 967-997. doi:10.1590/S167939512011000400003

European Commission. (2011). The future of rural development policy. Retrieved from http://ec.europa.eu/agriculture/policy-perspectives/policy-briefs/04_en.pdf

Gesthuizen, M. (2006). How socially committed are the Dutch Low-educated? Historical trend, life-course changes, and two explanations for educational differences. European Sociological Review, 22(1), 91-105. doi:10.1093/esr/jci045

Getz, D., \& Carlsen, J. (2000). Characteristics and goals of family and owner operated businesses in the rural tourism and hospitality sectors. Tourism Management, 21(6), 547-560. doi:10.1016/S0261-5177(00)00004-2

Getz, D., \& Carlsen, J. (2005). Family business in tourism: State of the art. Annals of Tourism Research, 32(1), 237-258. doi:10.1016/j.annals.2004.07.006

Greve, A., \& Salaff, J. W. (2003). Social networks and entrepreneurship. Entrepreneurship: Theory \& Practice, 28(1), 1-22. doi:10.1111/1540-8520.00029

Inkpen, A. C., \& Tsang, E. W. K. (2005). Social capital, networks, and knowledge transfer. Academy of Management Review, 30(1), 146-165. doi:10.5465/AMR.2005.15281445

Johnstone, H., \& Lionais, D. (2014). Depleted communities and community business entrepreneurship: Revaluing space through place. Entrepreneurship \& Regional Development, 16(3), 217-233. doi:10.1080/0898562042000197117

Johannisson, B. (1998). Personal networks in emerging knowledge-based firms: Spatial and functional patterns. Entrepreneurship and Regional Development, 10(4) 297-312. doi:10.1080/08985629800000017

Kaariainene, J., \& Lehtonen, H. (2006). The variety of social capital in welfare state regimes - a comparative study of 21 countries. European Societies, 8(1), 27-57. doi:10.1080/14616690500491399

Karlsson, S. E. (2005). The social and the cultural capital of a place and their influence on the production of tourism: A theoretical reflection based on an illustrative case study. Scandinavian Journal of Hospitality and Tourism, 5(2), 102-115. doi:10.1080/15022250510014408

Li, Y., Wang, X., Huang, L., \& Bai, X. (2013). How does entrepreneurs' social capital hinder new business development? A relational embeddedness perspective. Journa of Business Research, 66(12), 2418-2424. doi:10.1016/j.jbusres.2013.05.029

Liao, J., \& Welsch, H. (2005). Roles of social capital in venture creation: Key dimensions and research implications. Journal of Small Business Management, 43(4) 345-362. doi:10.1111/j.1540-627X.2005.00141.

Lockett, A., Thompson, S. \& Morgenstern, U. (2009). The development of the resource-based view of the firm: A critical appraisal. International Journal of Management Reviews, 11(1), 9-28. doi:10.1111/j.1468-2370.2008.00252x

Lockett, A., \& Wild, A. (2014). Bringing history (back) into the resource-based view. Business History, 56(3), 372-390. doi:10.1080/00076791.2013.790371

Manolova, T., Manev, I., Carter, N., \& Gyoshev, B. (2006). Breaking the family and friends' circle: Predictors of external financing usage among men and women entrepreneurs in a transitional economy. Venture Capital, 8(2), 109-32. doi:10.1080/13691060500434072

Mendonça, M. C. (2006). Gestão integrada do turismo no espaço rural (Tese de doutorado não publicada). Universidade Federal de São Carlos, São Carlos, SP.
Meyer-Cech, K. (2005). Regional cooperation in rural theme trails. In D. Hall, I. Kirkpatrick, \& M. Mitchell (Eds.), Rural tourism and sustainable business (pp. 137148). Clevedon: Channel View.

Murzyn-Kupisz, M. (2012). Cultural economic and social sustainability of heritage tourism: Issues and challenges. Economic and Environmental Studies, 12(2), 113-133. Nahapiet, J., \& Ghoshal, S. (1998). Social capital, intellectual capital, and the organizational advantage. Academy of Management Review, 23(2), 242-266.

Narayanan, V. K., Colwell, K., \& Douglas, F. L. (2009). Building organizational and scientific platforms in the pharmaceutical industry: A process perspective on the development of dynamic capabilities. British Journal of Management, 20(Suppl. s1) S25-S40. doi:10.1111/j.1467-8551.2008.00611.x

Nordin, S., \& Westlund, H. (2009). Social capital and the life cycle model: The transformation of the destination of Are. Tourism: An International Interdisciplinary Journal, 57(3), 259-284.

Ohe, Y., \& Kurihara, S. (2013). Evaluating the complementary relationship between local brand farm products and rural tourism: Evidence from Japan. Tourism Management, 35, 278-283. doi:10.1016/j.tourman.2012.07.003

Pandza, K., \& Thorpe, R. (2009). Creative search and strategic sense-making: Missing dimensions in the concept of dynamic capabilities. British Journal of Management 20(Suppl. s1), S18-S131. doi:10.1111/j.1467-8551.2008.00616.x

Park, D., Lee, K., Choi, H., \& Yoon, Y. (2012). Factors influencing social capital in rura tourism communities in South Korea. Tourism Management, 33(6), 1511-1520. doi:10.1016/j.tourman.2012.02.005

Pego, A. C. H. C. D. \& Bernardo, M. R. A. M. (2015). The impact of technology and information systems in rural tourism in the Algarve region. Dos Algarves: $A$ Multidisciplinary e-Journal, (25), 39-59.

Pichler, F., \& Wallace, C. (2007). Patterns of formal and informal social capital in Europe. European Sociological Review, 23(4), 423-435. doi:10.1093/esr/jcm013

Putnam, R. D. (2000). Bowling alone: The collapse and revival of American community New York, NY: Simon \& Schuster Paperbacks.

Saunders, M., Lewis, P., \& Thornhill, A. (2012). Research methods for business students (6th ed.). Harlow: Pearson Education.

Scheepers, P., Grotenhuis, M., \& Gelissen, J. (2002). Welfare state dimensions of social capital: Cross-national comparisons of social contacts. European countries. European Societies, 4(2), 185-207. doi:10.1080/14616690220142781

Schofer, E., \& Fourcade-Gourinchas, M. (2001). The structural context of civic engagement: Voluntary association membership in comparative perspective. American Sociological Review, 66(6), 806-828.

Steyaert, C., \& Katz, J. (2004). Reclaiming the space of entrepreneurship in society: Geographical, discursive and social dimensions. Entrepreneurship \& Regional Development, 16(3), 179-196. doi:10.1080/0898562042000197135

$\mathrm{Su}$, B. (2011). Rural tourism in China. Tourism Management, 32(6), 1438-1441. doi:10.1016/j.tourman.2010.12.005

Tsai, W., \& Ghoshal, S. (1998). Social capital and value creation: The role of intrafirm networks. Academy of Management Journal, 41(4), 464-476.

Van Der Gaag, M., \& Snijders, T. A. B. (2004). The resource generator: Social capital quantification with concrete items. Social Networks, 27(1), 1-29. doi:10.1016/j.socnet.2004.10.001

Van Oorschot, W. V., \& Arts, W. (2005). The social capital of European welfare states: The crowding out hypothesis revisited. Journal of European Social Policy, 15(1), 5-26. doi:10.1177/0958928705049159

Yin, R. K. (2009). Case study research: Design and methods (4th ed.). Thousand Oaks, CA: Sage.

Yin, R.K. (2005). Estudo de Caso. Planejamento e Métodos. Porto Alegre: Bookman. Zhao, W., Ritchie, J., \& Echtner, C. (2011). Social capital and tourism entrepreneurship. Annals of Tourism Research, 38(4), 1570-1593.

Recebido: 11.02.2015

Reenviado: 20.07.2016

Aceite: 21.07 .2016 